\title{
Validation of the Danish 7-day pre-coded food diary among adults: energy intake $v$. energy expenditure and recording length
}

\author{
Anja Biltoft-Jensen*, Jeppe Matthiessen, Lone B. Rasmussen, Sisse Fagt, Margit V. Groth and Ole Hels \\ Department of Nutrition, National Food Institute, Technical University of Denmark, Mørkhøj Bygade 19, DK-2860 Søborg, \\ Denmark
}

(Received 6 January 2009 - Revised 30 April 2009 - Accepted 29 June 2009 - First published online 4 August 2009)

Under-reporting of energy intake (EI) is a well-known problem when measuring dietary intake in free-living populations. The present study aimed at quantifying misreporting by comparing EI estimated from the Danish pre-coded food diary against energy expenditure (EE) measured with a validated position-and-motion instrument $\left(\right.$ ActiReg $\left.^{\circledR}\right)$. Further, the influence of recording length on EI:BMR, percentage consumers, the number of meal occasions and recorded food items per meal was examined. A total of 138 Danish volunteers aged 20-59 years wore the ActiReg ${ }^{\circledR}$ and recorded their food intake for 7 consecutive days. Data for 2504 participants from the National Dietary Survey 2000-2 were used for comparison of characteristics and recording length. The results showed that EI was underestimated by $12 \%$ on average compared with EE measured by ActiReg ${ }^{\circledR}$ (PreMed AS, Oslo, Norway). The $95 \%$ limits of agreement for EI and EE were -6.29 and 3.09 MJ/d. Of the participants, $73 \%$ were classified as acceptable reporters, $26 \%$ as under-reporters and $1 \%$ as over-reporters. EI:BMR was significantly lower on 1-3 consecutive recording days compared with 4-7 recording days $(P<0 \cdot 03)$. Percentage consumers of selected food items increased with number of recording days. When recording length was $7 \mathrm{~d}$, the number of reported food items per meal differed between acceptable reporters and under-reporters. EI:BMR was the same on 4 and 7 consecutive recording days. This was, however, a result of under-reporting in the beginning and the end of the $7 \mathrm{~d}$ reporting. Together, the results indicate that EI was underestimated at group level and that a $7 \mathrm{~d}$ recording is preferable to a $4 \mathrm{~d}$ recording period.

Denmark: Dietary intake: Food diaries: Misreporting: Reporting status: ActiReg ${ }^{\circledR}$

The assessment of dietary intake plays a vital role in many aspects of nutritional science. Dietary intake data are, among others, used for monitoring intakes of foods and nutrients to identify public health nutrition problems, analysing and identifying the associations between dietary intake, health and disease, and estimating dietary exposure from contaminants, pesticides and additives. Results are used as a basis for far-reaching policy decisions and initiatives, including the development of food-based dietary guidelines, aimed at improving health and food safety in the general population. The Danish National Survey of Dietary Habits and Physical Activity 2000-2 (National Dietary Survey 2000-2) uses a $7 \mathrm{~d}$ pre-coded food diary (food diary) to collect information about the current dietary intake in the population. The method was chosen because it is suitable both for children and adults as well as being cost efficient. Working groups established by the Nordic Council of Ministers investigated and recommended the use of this method to harmonise dietary assessment methods used in the Nordic countries ${ }^{(1)}$. The National Dietary Survey 2000-2 method is, however, burdensome because the respondent has to complete a food diary every day for $7 \mathrm{~d}$. Thus, studies indicate that the $7 \mathrm{~d}$ method applied in the National Dietary Survey 2000-2 may lead to misreporting due to participant fatigue and modification in usual dietary habits ${ }^{(2,3)}$, and use of shorter recording periods is often applied ( 3 or $4 \mathrm{~d}$ ) in prospective dietary surveys ${ }^{(4)}$. It is also assumed that a shorter recording period may help optimise overall participation because of the lower burden.

To know the extent of misreporting and especially underreporting, evidence of the validity of the survey instrument is required, preferably against an objective measure, to ensure that the survey instrument does not seriously bias the perceived relationship between dietary intake and health. The food diary has been developed and improved since 1995, where it was validated in relation to weighed food records and measurements of $\mathrm{N}$ in $24 \mathrm{~h}$ urine samples. But low reporting of energy intake (EI) has become an increasing problem in the National Dietary Survey 2000-2 $2^{(5)}$ since then. Therefore the purpose of the present study was to assess the validity of diet self-reporting in a group of Danish adult volunteers, by comparing self-reported EI measured by the food diary with energy expenditure (EE) using a validated position-and-movement monitor (ActiReg ${ }^{\circledR}$; PreMed AS, Oslo, Norway). Furthermore, the impact of prospective recording length on reporting status, i.e. the reported EI:calculated $\mathrm{BMR}$ ratio $(\mathrm{EI}: \mathrm{BMR})^{(6)}$ was examined to establish if it

Abbreviations: AR, acceptable reporters; EE, energy expenditure; EI, energy intake; National Dietary Survey 2000-2, Danish National Survey of Dietary Habits and

Physical Activity 2000-2; UR, under-reporters.

* Corresponding author: Dr Anja Biltoft-Jensen, fax +45 723471 19, email abpj@food.dtu.dk 
would be feasible to reduce recording length from 7 to $4 \mathrm{~d}$. The impact of a reduced recording length on the proportion of subjects consuming specific foods (percentage consumers), the number of meal occasions and food items per meal was also investigated.

\section{Methods}

\section{Study design}

The participants completed the food diary each day for 7 consecutive days, every time they ate, resulting in a measure of EI. On the same days as the food diary was completed the participants wore ActiReg ${ }^{\circledR}$, an electronic device, resulting in a measure of EE. All participants were interviewed, in person, about social background, health issues, attitudes and knowledge about food, health and physical activity. Anthropometric measurements were made. Detailed instructions on how to record food consumption and how to use the ActiReg ${ }^{\circledR}$ instrument were provided individually to all participants. Written instructions were given as well. The procedures followed were in accordance with the Helsinki Declaration of the World Medical Association and the study was approved by the Danish Data Protection Agency. The study participants completed the same study protocol as participants in the National Dietary Survey 2000-2, except for the ActiReg ${ }^{\circledR}$ part and the anthropometric measurements.

\section{Participants}

A total of 143 healthy Danish volunteers, aged 20-59 years, were recruited in the Copenhagen area through advertisement in local workplaces, a local newspaper and a website. An equal representation of men and women in different age groups (20-29 years, 30-39 years, 40-49 years and 50-59 years) was aimed at. Pregnant women, athletes and subjects on a slimming diet were excluded.

Data for 2504 participants aged 20-59 years (1153 men and 1351 women) from the National Dietary Survey 2000-2 were included for comparison of characteristics, recording length and under-reporting.

\section{Danish pre-coded food diary}

Dietary intake was recorded for 7 consecutive days in food diaries supplied with pre-coded answer options for the most commonly eaten foods and dishes in the Danish diet. The questionnaire was organised according to the typical Danish meal pattern (breakfast, lunch, dinner and snacks). Each meal was divided into sections with headings such as beverages, bread, spreadable fats, cold meat cuts, meat, and vegetables to make it easier to find and record foods, dishes and beverages in the pre-coded food diary. For food items not included in the pre-coded food diary, the participants wrote type of food and portion size eaten in open-answer categories. The portion sizes were given in predefined household measures (for example, hot beverages in cups, cold beverages in glasses) or estimated from photographs. Each participant was also given a booklet containing twelve series of colour photographs, showing four to six different portions ranging from small to large.
The participants recorded in the food diary if they skipped a meal on purpose. Whenever participants had anything to drink and/or eat, they reported the time for the start and end of the meal and where it was consumed and prepared. The participants reported all food items eaten or drunk.

A trained interviewer instructed the participants on how to complete the food diary. All these instructions were given in the same way as in the National Dietary Survey 2000-2. The data were scanned using The Eyes \& Hands program (version 4.1, 1998; ReadSoft Ltd, Milton Keynes, Bucks, UK). The average EI was calculated for each individual using the software system GIES (version 0.995a, released 26 June 2005), developed at the National Food Institute, Technical University of Denmark, and the Danish Food Composition Databank (version 5; Søborg; Denmark; October 2002, www.Foodcomp.dk).

ActiReg $^{\circledR}$

ActiReg ${ }^{\circledR}$ (PreMed AS, Oslo, Norway) is an electronic device which records body position and movement. It has two body position sensors and two motion sensors connected by cables to a battery-operated storage unit. One pair of sensors is attached by medical tape to the chest (on the sternum) and the other to the front of the right thigh approximately midway between the knee and the hip. The storage unit is fixed to an elastic belt worn around the waist. Together, the sensors are able to discriminate between the body positions, standing, sitting, bending forward and lying down, and also register whether there is movement or not in each pair of sensors or both. The combination of body position and movement is checked every $1 \mathrm{~s}$ and stored in the unit, with one code for each combination. Further details of the description and validation of the ActiReg ${ }^{\circledR}$ method have been published elsewhere ${ }^{(7)}$.

The participants in the present study carried ActiReg ${ }^{\circledR}$ for the same 7 consecutive days as they recorded their food intake, except at night while sleeping or during water activities. If ActiReg ${ }^{\circledR}$ was not worn for a period of $15 \mathrm{~min}$ or more during the daytime, the participants were instructed to record the type of activity during that time on a form, and energy costs during non-wear time (showering and water activities) were assessed and added when the total EE for that particular day was calculated. If ActiReg ${ }^{\circledR}$ was not carried for $3 \mathrm{~h}$ or more and/or the wear time was $<10 \mathrm{~h}$ per $\mathrm{d}$, the day was excluded. The data collected were processed by a specially designed program (ActiCalc; NorthStar Solutions, Manhattan, KS, USA). Physical activity level (PAL) was calculated from the activity levels and body positions measured, as described by Hustvedt et al. ${ }^{(7)}$. BMR was calculated from the equation published by Garby et al. ${ }^{(8)}$ based on body composition data from measurements of electrical impedance ${ }^{(9)}$. EE was calculated for each individual as PAL $\times$ BMR. The mean of the acceptable/valid days was used to estimate EE.

\section{Anthropometric measurements}

Body weight, height and body composition were measured twice for all participants to obtain the same measure. Participants were weighed without shoes in light indoor clothing to 
the nearest $0 \cdot 1 \mathrm{~kg}$ on an electronic digital scale (Rowenta Silver Art; Rowenta France SAS, Vernon, France). Body weight was also measured after the recording period on the same scale in order to establish weight stability during the recording period. Height was measured without shoes to the nearest $1 \mathrm{~cm}$ with a Seca 222 (Vogel \& Halke $\mathrm{GmbH} \&$ Co., Hamburg, Germany). Body composition was measured with a hand-to-foot bioelectrical impedance analyser (Maltron BF-906; Maltron International Ltd, Rayleigh, Essex, UK) after at least $5 \mathrm{~min}$ rest in the supine position. Participants were instructed to avoid diuretic drinks $24 \mathrm{~h}$ before bioelectrical impedance testing (no alcohol and no coffee and/or tea in large amounts), not to take any meals at least $2 \mathrm{~h}$ before testing, and to abstain from exercise $12 \mathrm{~h}$ before testing.

\section{Definition of misreporters}

Since day-to-day variation in EI and in EE is normal, exact agreement between EI and EE over $7 \mathrm{~d}$ in one individual is unlikely. Therefore the accuracy of the reported EI was assessed using the confidence limits of agreement between reported EI and EE at the individual level as suggested by Black $^{(10)}$. This method for identifying misreporters has formerly been used in the present study population, and the details are published elsewhere ${ }^{(11)}$.

The same method was used to identify acceptable reporters (AR), under-reporters (UR) and over-reporters according to recording length.

For the definition of misreporters in the National Dietary Survey 2000-2, Goldberg's cut-off points for EI:BMR for $4 \mathrm{~d}(\mathrm{EI}: \mathrm{BMR}<1.06)^{(6)}$ and $7 \mathrm{~d}(\mathrm{EI}: \mathrm{BMR}<1 \cdot 1)^{(6)}$ were used. In the National Dietary Survey 2000-2 BMR was estimated from equations published in the Nordic Nutrition Recommendations ${ }^{(12)}$.

\section{Energy intake:BMR ratio in relation to recording length}

We compared EI:BMR in relation to duration of recording in the present study and in the National Dietary Survey 2000-2 to establish if it would be feasible to reduce recording length. In the present study, a similar trend of EI:BMR was observed throughout recording days, no matter if the starting day was a weekday or a weekend day. It was therefore decided to treat data as one group in order to have more observations. As Monday was over-represented as the starting day in the National Dietary Survey 2000-2, the number of individuals with this starting day was reduced by randomly removing approximately half of the population in each level of EI:BMR. This was done because the EI on weekend days was higher than on weekdays in the National Dietary Survey 2000-2. With Monday over-represented as the starting day, a difference between 4 and 7 recording days could be due to that reason only.

\section{Eating occasions and food items}

A measure of reporting habits - the mean number of eating occasions and food items recorded per eating occasion was established for AR and UR. To determine the number of eating occasions reported, all foods and beverages reported at one meal were assumed to constitute one eating occasion.
The number of different food items consumed at each eating occasion was also determined for AR and for UR. A food item could be a single food component, for example, a glass of water, or a multiple food component such as a sandwich.

Alcohol, two foods (apples and fish) and one beverage (soft drinks) were chosen to illustrate the impact of recording length on the percentage of consumers and to have foods at different levels. Apples and fish are basic foods whereas soft drinks and alcohol are non-basic foods. Furthermore, alcohol is a macronutrient, fish is a food group, and apples and soft drinks are food items.

\section{Statistics}

Differences in characteristics between the participants and the population in the National Dietary Survey 2000-2 were evaluated using the $\chi^{2}$ statistic, $z$ test (adjusted using the Bonferroni correction) and two-sample $t$ tests. The validity of estimated EI from the food diary was tested by comparison with EE measured with the ActiReg ${ }^{\circledR}$ using paired-sample $t$ tests. Agreement between the food diary and the ActiReg ${ }^{\circledR}$ was assessed by Bland-Altman plot ${ }^{(13)}$. Pearson correlation coefficients were also calculated. EI and EE were divided into quartiles and cross-classification was used to assess categorical agreement between the two methods. The impact of recording length on EI:BMR was examined using ANOVA with repeated measurements including EI:BMR as the dependent variable and number of consecutive recording days $(1,2, \ldots 7)$ as independent variables. Differences in the number of UR and AR were evaluated using a $\chi^{2}$ test and differences in food items reported per meal between 4 and 7 recording days were evaluated using ANOVA with repeated measurements. In this model the number of food items recorded was included as the dependent variable and the number of recording days (4 or 7) and reporting type (AR and UR) as independent variables.

In both repeated-measures ANOVA models, homogeneity of variance and normal distribution among residuals were verified by plots and histograms of residuals as well as by a Shapiro-Wilk test for normal distribution.

\section{Results}

A total of 143 subjects completed the study. Data from two participants were excluded due to technical problems with the ActiReg ${ }^{\circledR}$ equipment; two participants had mounted the ActiReg ${ }^{\circledR}$ sensors erroneously and one individual did not return the food diary, which left 138 participants with useful data. From these, $21 \mathrm{~d}$ of ActiReg $^{\circledR}$ measurements were excluded because of insufficient wear time, and another $20 \mathrm{~d}$ were omitted due to incorrect placement of the sensors. In the final study population, seven participants had repeated the study protocol due to technical problems with ActiReg ${ }^{\circledR}$.

Characteristics of the study population compared with the population in the Danish National Survey of Dietary Habits and Physical Activity 2000-2

The volunteer study population was representative of the randomly selected population in the National Dietary Survey 2000-2 with regard to sex, age and weight status, but differed 
significantly with regard to educational level, smoking habits and occupational activity. Compared with the National Dietary Survey 2000-2, the study population consisted of a higher proportion of individuals with a long education, fewer smokers, a higher proportion of participants with sedentary occupations and moderate leisure-time activity. The characteristics of the study population in comparison with the National Dietary Survey 2000-2 have been published elsewhere ${ }^{(14)}$.

\section{Dietary intake in the study population compared with the} population in the Danish National Survey of Dietary Habits and Physical Activity 2000-2

A higher proportion of the study population than in the National Dietary Survey 2000-2 avoided fat spread on rye bread. Moreover, the male study population seemed to be more aware of healthy eating and ate a diet with a lower fat content and higher fibre content compared with men in the National Dietary Survey 2000-2. However, the male study population had a higher sugar content in their diet whereas women had lower sugar content in their diet compared with the men and women in the National Dietary Survey 2000-2. Furthermore, the study population reported a significantly $(P<0.005)$ higher $(10 \%)$ EI compared with the population in the National Dietary Survey 2000-2 (Table 1).

\section{Energy intake (food diary) v. energy expenditure (ActiReg ${ }^{\circledR}$ )}

The differences between EI and EE were $-2 \cdot 1 \mathrm{MJ} / \mathrm{d}$ among males and $-1.2 \mathrm{MJ} / \mathrm{d}$ among females, with an average difference of $-1.6 \mathrm{MJ} / \mathrm{d}$ (Table 2) corresponding to a $12 \%$ lower EI than EE overall. The width for the $95 \%$ limits of agreement was -6.29 and $3.09 \mathrm{MJ} / \mathrm{d}$, which indicates wide discrepancies between the two methods (Fig. 1). The limits of agreement were broader in men $(-7.88$ to $3.78 \mathrm{MJ} / \mathrm{d})$ than in women $(-4.16$ to $1.84 \mathrm{MJ} / \mathrm{d})$. Almost all outliers were men.
Pearson's correlation coefficients between EI and EE were 0.56 for all participants $(P<0.001)$. Separated by sex, the correlation was $0.16(P=0.208)$ for men and 0.50 for women $(P=0.003)$. When male outliers $(n 5)$ were excluded, the correlation for men was $0 \cdot 30(P=0 \cdot 015)$.

When agreement between the methods was studied within the range of $\pm 10 \%$ of EE, $28 \%$ of the participants fell into this range. Twice as many $(60 \%)$ fell below and $12 \%$ fell above the range of agreement. More men than women were classified within this range of agreement.

The proportion of male participants appearing in the same quartile for both EI and EE was $20 \% ; 66 \%$ were classified into correct or adjacent quartiles, $24 \%$ were misclassified and $10 \%$ were grossly misclassified. For female participants, $23 \%$ were classified in the same quartile for both EI and EE; $79 \%$ were classified into correct or adjacent quartiles, $14 \%$ were misclassified and $7 \%$ were grossly misclassified.

\section{Reporting of energy intake in relation to reporting length}

The proportion of UR differed significantly between 4 and 7 reporting days both in the present study $(4 \mathrm{~d}=12 \%$; $7 \mathrm{~d}=26 \% ; P=0.003)$ and in the National Dietary Survey $2000-2(4 \mathrm{~d}=23 \% ; 7 \mathrm{~d}=24 \% ; P<0 \cdot 001)$.

Analysing the recording days separately, EI:BMR was lower on the 1, 2, 6 and 7th separate recording day compared with the middle days in the present study. In the National Dietary Survey 2000-2, EI:BMR was lower on days 1 and 7 compared with the middle days (Table 3).

Analysing the recording days consecutively, EI:BMR was significantly lower on day $1,1-2$, and 1-3 consecutive recording days compared with 4-7 recording days $(P<0.032)$. The same results were seen in the National Dietary Survey $2000-2$ except that only EI:BMR on days $1-2$ was lower than on days 3-7 $(P<0 \cdot 006)$ (Fig. 2).

Table 1. Dietary composition, avoidance of fat spread on bread and intention to eat healthily, by sex, in the validation study (present study) and in the Danish National Survey of Dietary Habits and Physical Activity $2000-2$ (National Dietary Survey 2000-2) (20-59 years)

(Mean values and standard deviations)

\begin{tabular}{|c|c|c|c|c|c|c|c|c|}
\hline & \multicolumn{4}{|c|}{ Validation study ${ }^{\star}(n$ 138) } & \multicolumn{4}{|c|}{ National Dietary Survey 2000-2 (n 2504) } \\
\hline & \multicolumn{2}{|c|}{ Men (n 68) } & \multicolumn{2}{|c|}{ Women $(n 70)$} & \multicolumn{2}{|c|}{ Men $(n 1153)$} & \multicolumn{2}{|c|}{ Women ( $n$ 1351) } \\
\hline & Mean & SD & Mean & SD & Mean & SD & Mean & SD \\
\hline Subjects (\%) & \multicolumn{2}{|c|}{49} & \multicolumn{2}{|c|}{51} & \multicolumn{2}{|c|}{46} & \multicolumn{2}{|c|}{54} \\
\hline \multicolumn{9}{|l|}{ Dietary composition } \\
\hline Energy intake (MJ) & 11.9 & $2 \cdot 3$ & $9 \cdot 0$ & 1.6 & $10 \cdot 7^{\star}$ & 2.9 & $8 \cdot 2^{*}$ & $2 \cdot 2$ \\
\hline Fat (\% energy) & $31 \cdot 3$ & 4.9 & $31 \cdot 3$ & 4.5 & $33 \cdot 2^{*}$ & 5.5 & $31 \cdot 7$ & $5 \cdot 2$ \\
\hline Carbohydrate (\% energy) & $49 \cdot 0$ & $5 \cdot 8$ & $50 \cdot 7$ & $4 \cdot 7$ & $45 \cdot 8^{*}$ & 6.5 & $49 \cdot 4^{*}$ & $6 \cdot 2$ \\
\hline Protein (\% energy) & $14 \cdot 6$ & $2 \cdot 4$ & $14 \cdot 2$ & 1.5 & $14 \cdot 1$ & $2 \cdot 2$ & $14 \cdot 3$ & $2 \cdot 2$ \\
\hline Alcohol (\% energy) & $5 \cdot 9$ & $5 \cdot 8$ & $4 \cdot 6$ & $3 \cdot 8$ & $7 \cdot 0$ & $6 \cdot 4$ & 4.7 & $5 \cdot 2$ \\
\hline Added sugar (\% energy) & 11.5 & $7 \cdot 4$ & $8 \cdot 5$ & 3.9 & $9 \cdot 0^{*}$ & 5.5 & $9 \cdot 8^{*}$ & $5 \cdot 7$ \\
\hline Dietary fibre (g/10 MJ) & $21 \cdot 7$ & $5 \cdot 8$ & $24 \cdot 4$ & $5 \cdot 9$ & $20 \cdot 0^{*}$ & $5 \cdot 9$ & $23 \cdot 1$ & $7 \cdot 0$ \\
\hline \multicolumn{9}{|l|}{ Avoid fat spread on bread (\%) } \\
\hline Rye bread & \multicolumn{2}{|c|}{$45 \cdot 6$} & \multicolumn{2}{|c|}{$64 \cdot 3$} & \multicolumn{2}{|c|}{$28 \cdot 5^{\star}$} & \multicolumn{2}{|c|}{$48 \cdot 4^{*}$} \\
\hline Wheat bread & \multicolumn{2}{|c|}{$20 \cdot 6$} & \multicolumn{2}{|c|}{12.9} & \multicolumn{2}{|c|}{$13 \cdot 4$} & \multicolumn{2}{|c|}{$20 \cdot 3$} \\
\hline \multicolumn{9}{|l|}{ Intention to eat healthily (\%)† } \\
\hline 'Very often' and 'often' & \multicolumn{2}{|c|}{$75 \cdot 0$} & \multicolumn{2}{|c|}{$81 \cdot 4$} & \multicolumn{2}{|c|}{$58 \cdot 6^{*}$} & \multicolumn{2}{|c|}{$81 \cdot 2$} \\
\hline
\end{tabular}

* Value was significantly different from that of subjects of the same sex in the validation study $(P<0.05)$.

†Intentions to eat healthily were measured by asking to what extent the participants intended to eat healthily. The four response categories were: 'very often', 'often', 'once in a while' and 'never'. 
Table 2. Reporting characteristics of the study population (Mean values and standard deviations)

\begin{tabular}{|c|c|c|c|c|c|c|}
\hline & \multicolumn{2}{|c|}{ Men $(n 68)$} & \multicolumn{2}{|c|}{ Women $(n 70)$} & \multicolumn{2}{|c|}{ All $(n 138)$} \\
\hline & Mean & SD & Mean & SD & Mean & SD \\
\hline Body weight before recording $(\mathrm{kg})$ & $84 \cdot 8$ & $13 \cdot 2$ & $69 \cdot 1^{*}$ & $9 \cdot 8$ & $76 \cdot 8$ & 14.0 \\
\hline Body weight after recording $(\mathrm{kg})$ & 84.5 & $13 \cdot 0$ & $68 \cdot 9^{*}$ & $9 \cdot 7$ & $76 \cdot 6$ & $13 \cdot 8$ \\
\hline Fat-free body mass (\%) & 76.5 & $6 \cdot 4$ & $68 \cdot 2$ & $6 \cdot 4$ & $72 \cdot 3$ & $7 \cdot 6$ \\
\hline Fat body mass (\%) & 23.5 & $6 \cdot 4$ & 31.8 & $6 \cdot 4$ & $27 \cdot 7$ & 7.6 \\
\hline El $(\mathrm{MJ} / \mathrm{d})$ & 11.9 & $2 \cdot 3$ & $9 \cdot 0^{*}$ & 1.6 & $10 \cdot 4$ & $2 \cdot 5$ \\
\hline$E E(M J / d)$ & $13 \cdot 9$ & $2 \cdot 2$ & $10 \cdot 2^{*}$ & $1 \cdot 1$ & $12 \cdot 0$ & $2 \cdot 5$ \\
\hline BMR (MJ/d) & $8 \cdot 1$ & 0.9 & $6 \cdot 1^{*}$ & 0.5 & $7 \cdot 0$ & $1 \cdot 3$ \\
\hline$E I-E E(M J / d)$ & $-2 \cdot 1$ & $2 \cdot 9$ & $-1 \cdot 2^{\star}$ & 1.5 & -1.6 & $2 \cdot 3$ \\
\hline PAL & 1.73 & 0.17 & 1.68 & 0.14 & 1.71 & 0.15 \\
\hline $\mathrm{EI}: \mathrm{EE}(\mathrm{MJ} / \mathrm{d})$ & 0.87 & 0.19 & 0.89 & 0.14 & 0.88 & 0.17 \\
\hline EI:BMR & 1.50 & 0.36 & 1.50 & 0.27 & 1.5 & 0.31 \\
\hline Acceptable reporters (\%)† & \multicolumn{2}{|c|}{68} & \multicolumn{2}{|c|}{77} & \multicolumn{2}{|c|}{73} \\
\hline Under-reporters (\%)‡ & \multicolumn{2}{|c|}{31} & \multicolumn{2}{|c|}{22} & \multicolumn{2}{|c|}{26} \\
\hline Over-reporters (\%)§ & \multicolumn{2}{|c|}{1} & \multicolumn{2}{|c|}{1} & \multicolumn{2}{|c|}{1} \\
\hline
\end{tabular}

El, energy intake; EE, energy expenditure; PAL, physical activity level.

${ }^{*}$ Mean value was significantly different from that of the men $(P<0.05)$.

† Acceptable reporters were defined as having a ratio of El:EE in the range $76-124 \%$.

¥Under-reporters were defined as having a ratio of El:EE $<76 \%$.

$\S$ Over-reporters were defined as having a ratio of El:EE $>124 \%$.

In the National Dietary Survey 2000-2 the EI:BMR was lower for both men and women (men, $P=0 \cdot 01$; women, $P=0 \cdot 02$ ) compared with the present study. In both studies, data for both men and women demonstrated the same trend over the number of recording days, and therefore the data in Fig. 2. were analysed together.

\section{Reporting of consumption of selected foods in relation to reporting length}

The number of eating occasions did not differ across the number of recording days (data not shown), either for UR or AR.

The number of food items recorded per meal did not differ between UR and AR on the first $4 \mathrm{~d}$ of registration, but differed significantly when recording length was $7 \mathrm{~d}$ (Table 4). This was primarily due to a lower registration of snacks $(P<0 \cdot 01)$.

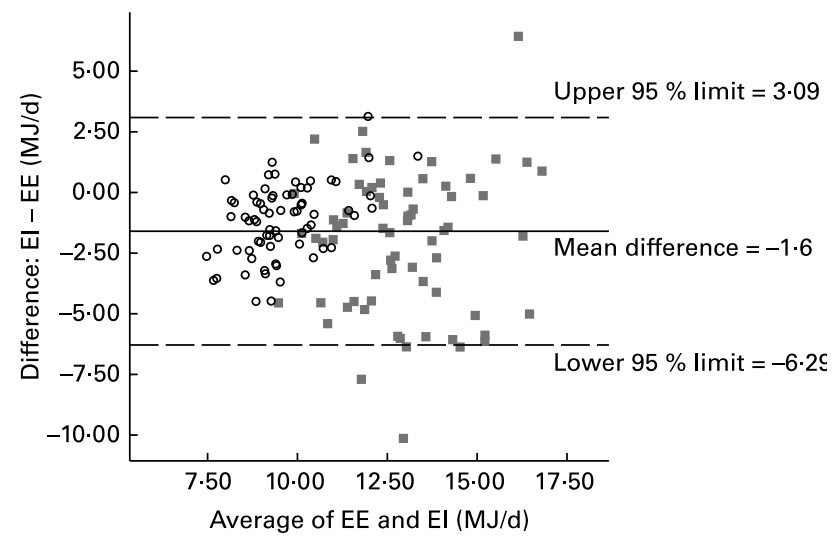

Fig. 1. Difference between energy intake (EI) calculated from the pre-coded food diary and energy expenditure (EE) measured with the ActiReg ${ }^{\circledR}$ plotted against the mean of EI and EE among adults ( $n$ 138). (-), Mean difference between the two methods; (---), 2 SD limits of agreement; $(\bigcirc)$, females; (口), males.
As can be seen in Table 5, the variance of the intake decreased and the percentage consumers increased while the median intake of consumers only decreased with the increasing number of recording days.

\section{Discussion}

Energy intake (food diary) v. energy expenditure (ActiReg ${ }^{\circledR}$ )

The study showed that in a motivated volunteer sample of Danish adults the average EI reported was underestimated by $12 \%$ compared with EE measured by the ActiReg ${ }^{\circledR}$. The limits of agreement were much broader in men than in women. This is because the BMR of women constitutes a larger part of total daily EE compared with men - so the variation among women is less. The size of under-reporting in the present study is in line with others using estimated records ${ }^{(15)}$. To the authors' knowledge only two other studies have used the ActiReg ${ }^{\circledR}$ method for assessing the validity of self-reported EI from $4 \mathrm{~d}$ pre-coded food diaries among children aged 9 and 13 years ${ }^{(16,17)}$. In the two Norwegian studies, a substantial under-reporting of EI was observed ranging from $18 \%$ among 9-year-olds ( $n$ 51) to 24-34\% among 13-year-olds depending whether the data collection period with the ActiReg ${ }^{\circledR}$ was $4 \mathrm{~d}$ ( $n$ 56) or $7 \mathrm{~d}$ ( $n$ 51). The high underestimation found in the Norwegian studies might be due to the use of a school class setting, which may have caused the children to compete against each other - resulting in an overestimation of activity.

In the present study, the ability of the food diary to rank individuals according to $\mathrm{EE}$ was moderate $(r \quad 0 \cdot 56)^{(18)}$. Approximately the same ability to rank individuals was observed in the child study by Andersen et al. ${ }^{(17)}$.

\section{$7 d$ v. $4 d$ of consecutive recording}

Reducing the recording period from 7 to 4 consecutive days did not change EI:BMR at the group level. It is, however, 
Table 3. Energy intake:BMR by recording day in the validation study (present study) $(n 138)$ and in the Danish National Survey of Dietary Habits and Physical Activity 2000-2 (National Dietary Survey 2000-2) ( $n$ 2034*) (20-59 years)

(Mean values and standard deviations)

\begin{tabular}{|c|c|c|c|c|c|c|c|c|c|c|c|c|c|c|}
\hline \multirow[t]{2}{*}{ Reporting day... } & \multicolumn{2}{|c|}{1} & \multicolumn{2}{|c|}{2} & \multicolumn{2}{|c|}{3} & \multicolumn{2}{|c|}{4} & \multicolumn{2}{|c|}{5} & \multicolumn{2}{|c|}{6} & \multicolumn{2}{|c|}{7} \\
\hline & Mean & SD & Mean & SD & Mean & SD & Mean & SD & Mean & SD & Mean & SD & Mean & SD \\
\hline Validation study & $1.5^{\mathrm{c}}$ & 0.5 & $1 \cdot 4^{\mathrm{c}}$ & 0.5 & $1 \cdot 6^{\mathrm{b}, \mathrm{c}}$ & 0.6 & $1 \cdot 7^{\mathrm{a}}$ & 0.7 & $1 \cdot 6^{\mathrm{a}, \mathrm{b}}$ & 0.6 & $1 \cdot 5^{\mathrm{c}}$ & 0.5 & $1.4^{\mathrm{c}}$ & 0.6 \\
\hline National Dietary Survey 2000-2 & $1 \cdot 3^{\mathrm{c}, \mathrm{b}}$ & 0.5 & $1 \cdot 4^{\mathrm{a}, \mathrm{b}}$ & 0.5 & $1.4^{\mathrm{a}, \mathrm{b}}$ & 0.6 & $1 \cdot 4^{\mathrm{a}, \mathrm{b}}$ & 0.5 & $1 \cdot 4^{\mathrm{a}, \mathrm{b}}$ & 0.6 & $1 \cdot 4^{\mathrm{a}, \mathrm{b}}$ & 0.6 & $1 \cdot 3^{\mathrm{c}}$ & 0.5 \\
\hline
\end{tabular}

a,b,c Mean values within a row with unlike superscript letters were significantly different $(P<0.05)$.

*As Monday was over-represented as the starting day in the National Dietary Survey $2000-2$, the number of individuals with this starting day was reduced by randomly removing approximately half of the population in each level of energy intake:BMR.

not acceptable to reduce the reporting period to $4 \mathrm{~d}$, because the non-significant difference between 4 and 7 recording days is a result of a lower EI:BMR at the start and at the end of the reporting period. It could be argued that the most precise measure of dietary intake is obtained from the middle days and that days $1-2$, where an 'experimenter' effect (an alteration in dietary behaviour due to participants' awareness of being observed) is present and the last day where a fatigue effect is present, should be omitted in data analysis. In such a case, $4 \mathrm{~d}$ would not be sufficient. The 'experimenter' effect and fatigue effect, however, are greater in the present study than in the National Dietary Survey 2000-2, probably caused by the extra workload with the ActiReg ${ }^{\circledR}$. Another study exploring trends in reported EI in adults also found an 'experimenter' effect and that reported EI was lowest on the first day of recording ${ }^{(19)}$.

The number of UR identified was lower with 4 consecutive recording days compared with 7 consecutive days in the present study and the National Dietary Survey 2000-2.
However, we found a larger difference in the proportion of UR between 4 and $7 \mathrm{~d}$ in the present study than in the National Dietary Survey 2000-2. This may be due to the fact that a greater proportion of participants started recording on a weekend day in the present study compared with the National Dietary Survey $2000-2(47$ v. $28 \%)$ resulting in a relatively higher EI at the beginning of the present study.

Analysis of the number of food items recorded per meal showed that the higher proportion of UR observed on the $7 \mathrm{~d}$ is not only due to a more valid identification of UR with a longer recording length, but also due to a lower number of food items, especially snacks, reported. So there seems to be a relative fatigue effect towards recording among UR.

Poppit et al. ${ }^{(20)}$ have also observed that snacks were omitted from $24 \mathrm{~h}$ recalls, although meals were well reported. How the reporting of snacks could be improved should be addressed in future studies.

Recording length also affects percentage consumers and food intake estimates of consumers only. A short recording

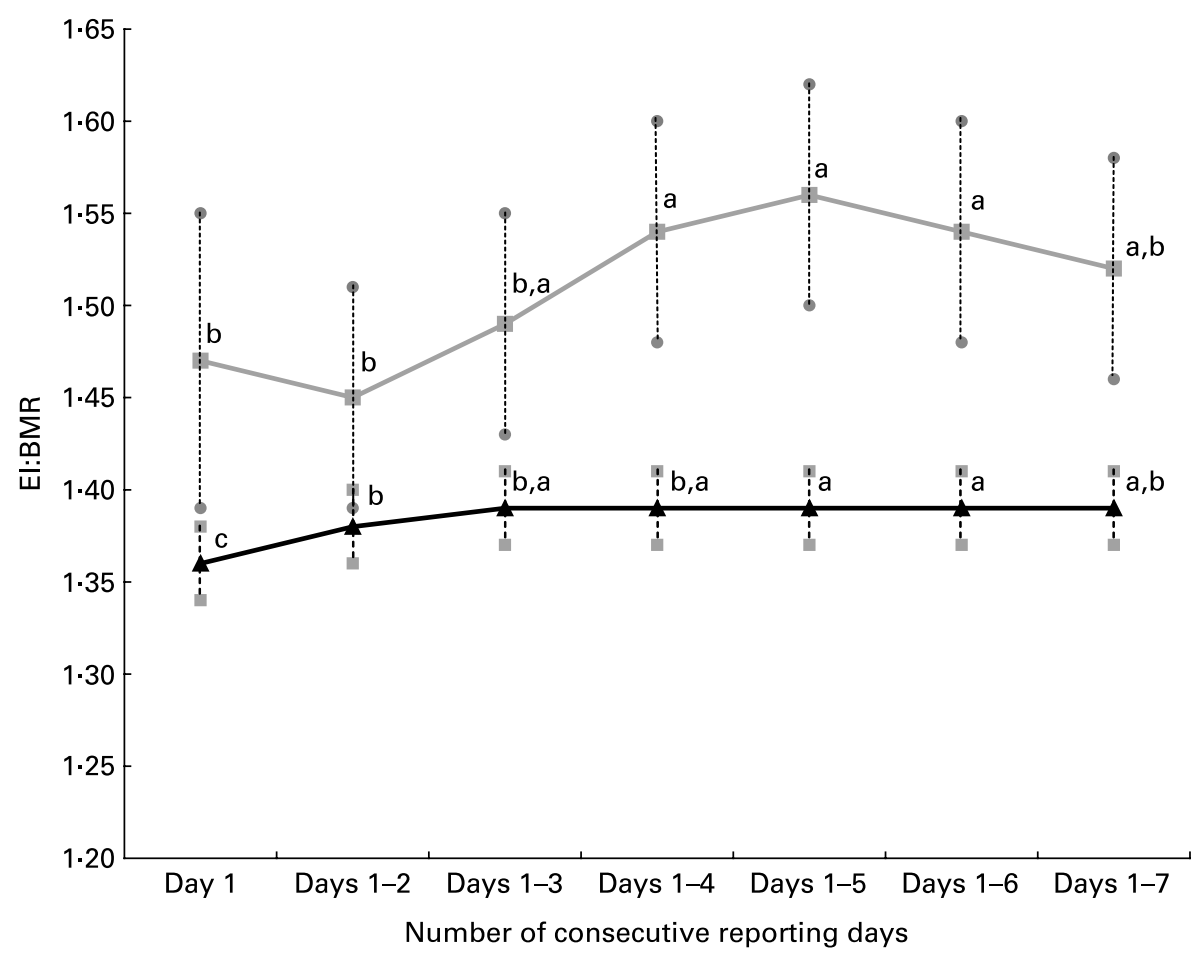

Fig. 2. Reported energy intake (EI):estimated BMR in relation to recording length in the present validation study ( $n$ 138; $\square$ ) compared with the Danish National Survey of Dietary Habits and Physical Activity $2000-2(n 2034 ; \boldsymbol{\Lambda})$. Values are means, with $95 \% \mathrm{Cl}$ represented by vertical bars. ${ }^{\text {a,b,c }}$ Mean values with unlike letters were significantly different across number of consecutive recording days $(P<0.05)$. 
period introduces a high degree of variation at the individual level and does not necessarily reflect the usual intake ${ }^{(21)}$. In the present study the variation of food intake decreased and the percentage consumers increased with increasing recording length. The percentage consumers of soft drinks, alcohol, apples and fish increased by approximately $10 \%$ with a $7 \mathrm{~d}$ recording period in comparison with a $4 \mathrm{~d}$ recording. This has also been observed for other foods in a study by Lambe et al. ${ }^{(2)}$, where at least $50 \%$ of non-consumers on day 1 became consumers over the subsequent $13 \mathrm{~d}$.

Since the National Dietary Survey 2000-2 is used to develop and evaluate the impact of food-based dietary guidelines, food consumption from the largest achievable proportion of consumers should be obtained. The longest possible recording length is therefore preferable in prospective studies. Otherwise, participants may erroneously be classified as low or high consumers. Recording over $7 \mathrm{~d}$ has the advantage of covering one complete cycle of a common human behaviour ${ }^{(23)}$ and is still acceptable and feasible.

A recent study concluded that the use of $3 \mathrm{~d}$ recording may distort the apparent composition of the diet and reporting periods longer than $3 \mathrm{~d}$ and ideally $7 \mathrm{~d}$ are preferable ${ }^{\circledR}$.

\section{Applicability of the method}

The strength of the present study was that an objective method was used to measure $\mathrm{EE}$, and is not likely to have any correlated error. No significant mean difference between EE measured with ActiReg $^{\circledR}$ and EE measured with doubly labelled water or indirect calorimetry has been demonstrated $^{(7)}$. Moreover, the ActiReg ${ }^{\circledR}$ is a less expensive technique compared with doubly labelled water and thereby enables more participants in a validation study. However, activities such as arm work, carrying loads and water activities are not well accounted for due to the way ActiReg $^{\circledR}$ is designed. Like other objective instruments used to measure EE among free-living subjects, the ActiReg ${ }^{\circledR}$ method shows considerable variation at the individual level.

Comparison of EI with EE rests on the energy balance concept, i.e. EI must equal $\mathrm{EE}$ in the recording period. This concept assumes that individuals only eat to obtain energy balance. The results indicate a general under-reporting of EI by $12 \%$ and indicate that the week of food registration hardly reflects usual intake. A small mean weight loss of $200 \mathrm{~g}$ at group level supports the results of under-reporting of EI but could also be due to changes in fat-free mass (and thereby water).

The results indicate that especially the male population in the validation study differed from the randomly selected population in the National Dietary Survey 2000-2 by being more health focused. Men in the present study had healthier dietary habits and more frequent intentions to eat healthily and were more physically active during leisure time than men in the National Dietary Survey 2000-2. Intentions to eat healthily has been shown to be related to the degree of under-reporting in the study of Rasmussen et al. ${ }^{(11)}$.

Table 5. Influence of recording length on percentage consumers and median consumer-only intakes for soft drinks, alcohol, apples and fish ( $n$ 138)

\begin{tabular}{lcccc}
\hline & & & \multicolumn{2}{c}{ Consumer-only intakes $(\mathrm{g} / \mathrm{d})$} \\
\cline { 3 - 5 } Food or beverage item & Duration of recording (d) & Consumers (\%) & Median & 25th and 75th percentiles \\
\hline Soft drinks & 4 & 51 & 125 & 63,300 \\
Alcohol & 7 & 59 & 129 & 57,257 \\
& 4 & 89 & 17 & 7,32 \\
Apples & 7 & 95 & 14 & 6,29 \\
Fish & 4 & 57 & 63 & 31,94 \\
& 7 & 67 & 54 & 27,89 \\
& 4 & 96 & 26 & 14,50 \\
& 7 & & 24 & 10,42 \\
\hline
\end{tabular}


The frequent intentions of males to eat healthily in the present study could have resulted in healthier eating habits caused by underestimation of portion sizes of less healthy foods or undereating of especially unhealthy snacks or a combination in the week of registration. A higher proportion of men than women were therefore characterised as UR and a higher proportion of men than women were grossly misclassified when assessing agreement between the methods.

The choice of a volunteer population is a limitation, which may impair the representativeness of the study results. However, at the time the study was conducted, a random sample was not possible because the design of the study puts a heavier workload on the participants than in the National Dietary Survey 2000-2. The fact that the study population was comprised of motivated and more educated individuals may have resulted in a more accurate reporting of food intake than in the National Dietary Survey 2000-2. Thus, under-reporting in the present study is lower than in the National Dietary Survey 2000-2. The present study therefore represents a better-case scenario and does not necessarily reflect the randomly selected population in the National Dietary Survey 2000-2. Other studies assessing the validity of food records also include selected samples of volunteers $^{(16,17,24)}$. Participants in the present study were nevertheless representative of the general population with regard to sex, age and BMI.

\section{Conclusion}

The results showed that in a volunteer population representing 'a better-case scenario' EI was underestimated by $12 \%$ at the group level, and that there was substantial variability in the accuracy of the food diary at the individual level. The ability to rank individuals according to EI when compared with EE was moderate. Reducing the recording period from 7 to 4 consecutive days did not change EI:BMR at the group level, but this seems more to be a result of under-reporting in the beginning (experimenter effect) and at the end of a $7 \mathrm{~d}$ reporting (fatigue effect), than the two reporting periods (4 and $7 \mathrm{~d}$ ) being equally precise. The percentages of consumers were higher with a $7 \mathrm{~d}$ recording.

Together, the present results support that a reporting period of $7 \mathrm{~d}$ is preferable to a $4 \mathrm{~d}$ recording period, and it should be further considered to run analysis on days 3-6, thereby limiting the experimenter effect and a possible fatigue effect.

\section{Acknowledgements}

The authors are grateful to Hanne-Jette Hinsch and especially Henrik Bach Hartkopp (Department of Nutrition, National Food Institute, Technical University of Denmark) for processing the data and for contribution to the data analysis.

A. B.-J., J. M. and L. B. R. were responsible for the study concept and the acquisition of the data. A B.-J., J. M., L. B. R., S. F. and M. V. G. were responsible for the study design and all authors took part in critical revision of the manuscript. O. H. provided statistical expertise. A. B.-J. drafted the manuscript.

The present study was internally funded.

There is no conflict of interest.

\section{References}

1. Nordic Council of Ministers (1994) Evaluering av den Svenske Kostholdsundersфkelsen Hulken - Anvendelighet $i$ andre Nordiske Land (Evaluation of the Swedish Dietary Survey 'Hulken' - Suitability in other Nordic Countries). (Report in Swedish with a summary in English). Copenhagen: TemaNord.

2. Lillegaard IT, Loken EB \& Andersen LF (2007) Relative validation of a pre-coded food diary among children, underreporting varies with reporting day and time of the day. Eur $J$ Clin Nutr 61, 61-68.

3. Rebro SM, Patterson RE, Kristal AR, et al. (1998) The effect of keeping food records on eating patterns. J Am Diet Assoc 98, 1163-1165.

4. European Food Consumption Survey Method (EFCOSUM) Group (2001) European Food Consumption Survey Method. TNO report V3766. Zeist, The Netherlands: TNO Nutrition and Food Research.

5. Fagt S, Biltoft-Jensen A, Matthiessen J, et al. (2008) Danskernes Kostvaner 1995-2006. Status og Udvikling med Fokus på Frugt og Gront samt Sukker (The Dietary Habits of Danes. Status and Trends with Focus on Fruits and Vegetables and Sugar). (Report in Danish with a summary in English). Copenhagen: Technical University of Denmark, National Food Institute.

6. Goldberg GR, Black AE, Jebb SA, et al. (1991) Critical evaluation of energy intake data using fundamental principles of energy physiology: 1. Deviation of cut-off limits to identify under-recording. Eur J Clin Nutr 45, 569-581.

7. Hustvedt BE, Christophersen A, Johnsen LR, et al. (2004) Description and validation of the ActiReg: a novel instrument to measure physical activity and energy expenditure. $\mathrm{Br} J$ Nutr 92, 1001-1008.

8. Garby L, Garrow JS, Jorgensen B, et al. (1988) Relation between energy expenditure and body composition in man: specific energy expenditure in vivo of fat and fat-free tissue. Eur J Clin Nutr 42, 301-305.

9. Heitmann BL (1990) Prediction of body water and fat in adult Danes from measurement of electrical impedance. A validation study. Int J Obes 14, 789-802.

10. Black AE (2000) The sensitivity and specificity of the Goldberg cut-off for EI:BMR for identifying diet reports of poor validity. Eur J Clin Nutr 54, 395-404.

11. Rasmussen LB, Matthiessen J, Biltoft-Jensen A, et al. (2007) Characteristics of misreporters of dietary intake and physical activity. Public Health Nutr 10, 230-237.

12. Nordic Council of Ministers (2004) Nordic Nutrition Recommendations 2004. Integrating Nutrition and Physical Activity. Nord, 4th ed. Copenhagen: Nordic Council of Ministers.

13. Bland JM \& Altman DG (1986) Statistical methods for assessing agreement between two methods of clinical measurement. Lancet i, 307-310.

14. Matthiessen J, Biltoft-Jensen A, Rasmussen LB, et al. (2008) Comparison of the Danish Physical Activity Questionnaire with a validated position and motion instrument. Eur J Epidemiol 23, 311-322.

15. Livingstone MB \& Black AE (2003) Markers of the validity of reported energy intake. J Nutr 133, Suppl. 3, 895S-920S.

16. Lillegaard IT \& Andersen LF (2005) Validation of a pre-coded food diary with energy expenditure, comparison of underreporters $v$. acceptable reporters. Br J Nutr 94, 998-1003.

17. Andersen LF, Pollestad ML, Jacobs DR Jr, et al. (2005) Validation of a pre-coded food diary used among 13-yearolds: comparison of energy intake with energy expenditure. Public Health Nutr 8, 1315-1321.

18. Altman DG (1999) Practical Statistics for Medical Research. London: Chapman \& Hall. 
19. Whybrow S, Horgan G \& Stubbs RJ (2008) Low-energy reporting and duration of recording period. Eur J Clin Nutr 62, 1148-1150.

20. Poppitt SD, Swann D, Black AE, et al. (1998) Assessment of selective under-reporting of food intake by both obese and non-obese women in a metabolic facility. Int $J$ Obes Relat Metab Disord 22, 303-311.

21. Lambe J \& Kearney J (1999) The influence of survey duration on estimates of food intakes - relevance for food-based dietary guidelines. Br J Nutr 81, Suppl. 2, S139-S142.
22. Lambe J, Kearney J, Leclercq C, et al. (2000) The influence of survey duration on estimates of food intakes and its relevance for public health nutrition and food safety issues. Eur J Clin Nutr 54, 166-173.

23. de Castro JM (1991) Weekly rhythms of spontaneous nutrient intake and meal pattern of humans. Physiol Behav 50, 729-738.

24. Koebnick C, Wagner K, Thielecke F, et al. (2005) An easy-touse semiquantitative food record validated for energy intake by using doubly labelled water technique. Eur J Clin Nutr 59, 989-995. 